\title{
COMBINED THERAPY WITH CEPHALOTHIN, KANAMYCIN AND COLISTIN IN PATIENTS WITH PRESUMED BACTEREMIA* $\dagger$
}

\author{
Robert Thoburn, M.D. $\ddagger$ and F. Robert FeKeTy, JR., M.D. $\S$ \\ Department of Internal Medicine, University of Michigan Medical School, Ann Arbor, \\ Michigan, U.S.A.
}

(Received 24 April 1969; in revised form 30 July 1969)

\begin{abstract}
A BASIC premise of this study is that it is desirable to treat patients with Gram-negative bacteremia with an appropriate antibiotic in the early stages of the infection. This does not mean that other therapeutic measures can be ignored; indeed, we wish to emphasize the importance of incision and drainage of abscesses, relief of urinary obstruction, removal of infected foreign bodies, monitoring of central venous pressure, restoration of intravascular volume, and use of appropriate vasoactive amines. In most cases even the best antibiotic therapy will not succeed unless attention is given to these other measures. The beneficial effects of antibiotics are often slow to be noticed; they cannot be evidenced until many infecting bacteria are inhibited or killed, and reparative processes begin. We emphasize these other aspects of the treatment of infection because we will devote the rest of this paper to a discussion of a potent and potentially dangerous antibiotic regimen, especially when used by those unfamiliar with its properties. Nephrotoxicity and ototoxicity are the major problems. The vast majority of patients with infections do not require this regimen; it should be used only for serious infections, even then infrequently and selectively; and only by those who have become familiar with the proper use of these antibiotics. The regimen does not negate the need for appropriate cultures to document the nature of the infection.

We observed 50 patients at The Johns Hopkins Hospital treated with a regimen consisting of cephalothin, kanamycin, and colistin (33 patients were treated with intravenous polymyxin B sulfate instead of intramuscular colistin methanesulfonate). For the rest of this paper we shall refer to this regimen as CKC. We will tell why this regimen became popular, what its efficacy seemed to be, and what its toxicity has been.
\end{abstract}

\footnotetext{
*Supported by grants (AI-00344-01, AI-05780, and FR-05383-05) from the NIH; and gifts from Bristol Laboratories, Burroughs Wellcome and Company. Inc., Eli Lilly and Company, and the Warner-Lambert Research Institute.

†Part of this work was performed while the authors were at The Johns Hopkins Medical School, Baltimore, Maryland.

‡Formerly Epidemic Intelligence Service Officcr, National Communicable Disease Center, U.S.P.H.S., Atlanta, Ga.

§Address reprint requests to Dr. Fekety at University Hospital, 1405 E. Ann Street, Ann Arbor, Michigan, 48104.
} 


\section{METHODS}

When we noted that CKC was being used frequently at The Johns Hopkins Hospital, we decided to locate and follow as many of the adult patients being treated with it as possible. Case finding was facilitated by notification from the hospital pharmacy when all three antibiotics were ordered for a patient, by follow-up of patients with positive blood cultures, and by regular inquiries on the medical wards. Almost all of the patients were not under our direct care, and the study is thus a retrospective analysis of the regimen as used by others.

In general, the physicians using CKC selected it because they believed the patients had bacteremia caused by Gram-negative bacilli. Almost invariably, it was used before results of cultures, sensitivity tests, and other diagnostic measures were available. The regimen was popular because the preliminary results of a study of antibiotic combinations in our laboratory showed that $\mathrm{CKC}$ had very broad antibacterial activity.

Antibiotics were used parenterally, usually in the following dosages: cephalothin, 6-12 g/day; kanamycin, $1.0-1.5 \mathrm{~g} /$ day; colistimethate sodium, $5 \mathrm{mg} / \mathrm{kg} /$ day. Three patients received polymyxin $B$ sulfate intravenously (instead of colistin) in doses of $2.5 \mathrm{mg} / \mathrm{kg} / \mathrm{day}$, but no more than $200 \mathrm{mg} / \mathrm{day}$. Doses of kanamycin and colistin were reduced in patients with impaired renal function, but not according to any uniform guidelines.

Organisms were identified and their susceptibility to antibiotics was determined by the low concentration disc method in the routine clinical microbiology laboratory of the hospital by standard methods [1]. We also obtained many of these organisms, and determined their bacteriostatic and bactericidal susceptibility by serial broth dilution in tubes by methods detailed elsewhere [2]. A sample of laboratory stock strains of 60 Gram-negative bacilli (12 each of Esch. coli, Klebsiella-Enterobacter, Pseudomonas, Proteus mirabilis, and indol-positive Proteus species) was also studied in our laboratory by broth methods. Susceptibility to single antibiotics as well as to a mixture containing cephalothin $10 \mu \mathrm{g} / \mathrm{ml}$, kanamycin sulfate $20 \mu \mathrm{g} / \mathrm{ml}$, and colistin sulfate $5 \mu \mathrm{g} / \mathrm{ml}$ was determined on this sample, and the observed results with the mixture was compared with the expected results predicted from susceptibility tests with single antibiotics.

\section{RESULTS}

Ninety-four per cent of Gram-negative bacilli studied in our laboratory were inhibited at concentrations attainable in serum [3] by one or more antibiotics in the combination. In addition, pneumococci, Group A $\beta$ hemolytic streptococci, and coagulase-positive staphylococci were susceptible. Cephalothin and kanamycin were synergistic towards enterococci [3]. Thus, these organisms would probably be susceptible. Many other relatively rare coliforms would also be susceptible to one or more of them. Fungi are probably resistant, but this has not been examined. All three antibiotics in the combinations are bactericidal. It was the most frequently inhibitory antibiotic combination we studied. Thus, it was used in the Johns Hopkins Hospital primarily in serious, life-threatening infections where the nature of the etiologic agent could not readily be deduced by consideration of the site of the infection, the Gram-stain of exudate, the physical examination, and by bacteriologic results already available. It was intended as an emergency or stop-gap treatment, and one that was to be modified as soon as clinical and bacteriological results permitted. 


\section{Susceptibility of the organisms}

On the basis of the behavior of antibiotics tested singly, we predicted that 79 per cent of the laboratory strains we selected for special study would be inhibited by the mixture of CKC. The observed frequency of inhibition with the mixture was 87 per cent. Bactericidal action was predicted with 57 per cent of the strains; 77 per cent killing was actually observed. With none of the species was there evidence of antagonism in the mixtures.

The susceptibility data obtained with organisms isolated from the fifty patients treated with the combination in this study were also encouraging. These organisms are listed in Table 1. All bacteria isolated from these patients were susceptible to one or more of these three antibiotics. The results with $39 \mathrm{Gram}$-negative bacilli studied in our laboratory are summarized in Table 2. All of the organisms were sensitive to both kanamycin and colistin. A polymyxin is important in the combination because it is the only available drug with good activity towards Pseudomonas strains. We considered colistin to be the same as polymyxin $\mathrm{E}$.

An infection was ultimately well-documented in 88 per cent of the 50 patients; and in 95 per cent of the documented infections a Gram-negative bacillus was impli-

TABle 1. ORganisms isolated From Patients With DoCUMENTED INFECTIONS

\begin{tabular}{lcc}
\hline Organisms & Number of isolations & Percentage of total \\
\hline E. coli & 15 & 27.8 \\
Klebsiella-aerobacter & 11 & 20.4 \\
Paracolon & 6 & 11.1 \\
Pseudomonas & 5 & 9.3 \\
Proteus mirabilis & 4 & 7.4 \\
Anaerobic streptococci & 3 & 5.6 \\
Pneumococci & 2 & 3.7 \\
Staphylococcus aureus & 2 & 3.7 \\
Proteus vulgaris & 2 & 3.7 \\
Streptococcus fecalis & 1 & 1.9 \\
Staphylococcus albus & 1 & 1.9 \\
Proteus rettgeri & 1 & 1.9 \\
Hemophilus influenzae & 1 & 1.9 \\
\hline Total & 54 & \\
\hline
\end{tabular}

TABLE 2. SUSCEPTIBILITY OF THIRTY-NINE GRAM-NEGATIVE BACILLI ISOLATED FROM PATIENTS IN THE STUDY

\begin{tabular}{lcc}
\hline Antibiotics* & Number organisms sensitive & Percentage organisms sensitive \\
\hline Kanamycin, cephalothin and colistin & 39 & 100.0 \\
Kanamycin and colistin & 39 & 100.0 \\
Cephalothin and colistin & 36 & 92.4 \\
Kanamycin and cephalothin & 33 & 84.8 \\
Kanamycin & 31 & 79.5 \\
Colistin & 31 & 79.5 \\
Cephalothin & 26 & 66.8 \\
\hline
\end{tabular}

*Cephalothin $10 \mu \mathrm{g} / \mathrm{ml}$.

Kanamycin $20 \mu \mathrm{g} / \mathrm{ml}$.

Colistin $5 \mu \mathrm{g} / \mathrm{ml}$. 
cated. The infections are listed in Table 3. Bacteremia was documented in 14 of the 50 patients, or 28 per cent of the total; all of these organisms were Gram-negative bacilli (Table 4). Two patients had 2 episodes of bacteremia. Most of the patients with bacteremia had serious underlying diseases, and thus were relatively poor-risk patients. Their clinical details are presented in Table 5. A urinary tract infection was the apparent source of the bacteremia in most of the patients, and the infection was often related to instrumentation of the genitourinary tract or Foley catherization. In all but one of the patients with bacteremia, the infection was hospital-acquired. The therapeutic results in the patients with bacteremia are shown in Table 6.

Twenty-one ( 42 per cent) of the patients in this study died. Four ( 25 per cent) of the 16 episodes of bacteremia ended fatally. Oliguria with hypotension was an ominous sign in bacteremia, since 37.5 per cent of the patients with these signs died. The difference in fatality rates of bacteremic and non-bacteremic cases was not statistically significant.

It was especially difficult to estimate the efficacy of the regimen when the patients without bacteremia were considered. All we can say about the efficacy of the combination in these patients is that there were no obvious bacteriologic failures and that the rapidity of response was about what one might have expected for an appropriate antibiotic.

TABLE 3. INFECTIONS DIAGNOSED IN FIFTY PATIENTS RECEIVING CEPHALOTHIN, KANAMYCIN, AND COLISTIN*

\begin{tabular}{lccc}
\hline Type of infection & Number with bacteremia & Total number & Percentage of patients \\
\hline Urinary tract infection & 9 & 21 & 40.0 \\
Pneumonia & 1 & 13 & 22.0 \\
Bacteremia, source unknown & 4 & 4 & 8.0 \\
Wound infection & 0 & 3 & 4.0 \\
Peritonitis & 0 & 2 & 4.0 \\
Soft tissue abscess & 0 & 2 & 4.0 \\
Cholangitis & 1 & 1 & 2.0 \\
Phlebitis, catheter site & 1 & 1 & 2.0 \\
Pyometra & 0 & 1 & 2.0 \\
Cellulitis & 0 & 6 & 2.0 \\
Infection not proven & 0 & $55^{*}$ & 12.0 \\
\hline Total & 16 & & \\
\hline
\end{tabular}

*Some patients had more than 1 infection.

TABLE 4. ORGANISMS ISOLATED FROM THE BLOOD OF PATIENTS WITH BACTEREMLA*

\begin{tabular}{lc}
\hline \multicolumn{1}{c}{ Organism } & Number of patients \\
\hline Klebsiella-Aerobacter & 4 \\
E. coli & 4 \\
Paracolon & 3 \\
Pseudomonas & 3 \\
Proteus mirabilis & 1 \\
E. coli and Pseudomonas & 1 \\
\hline Total & 16 \\
\hline
\end{tabular}

*Two patients had 2 episodes of bacteremia. 


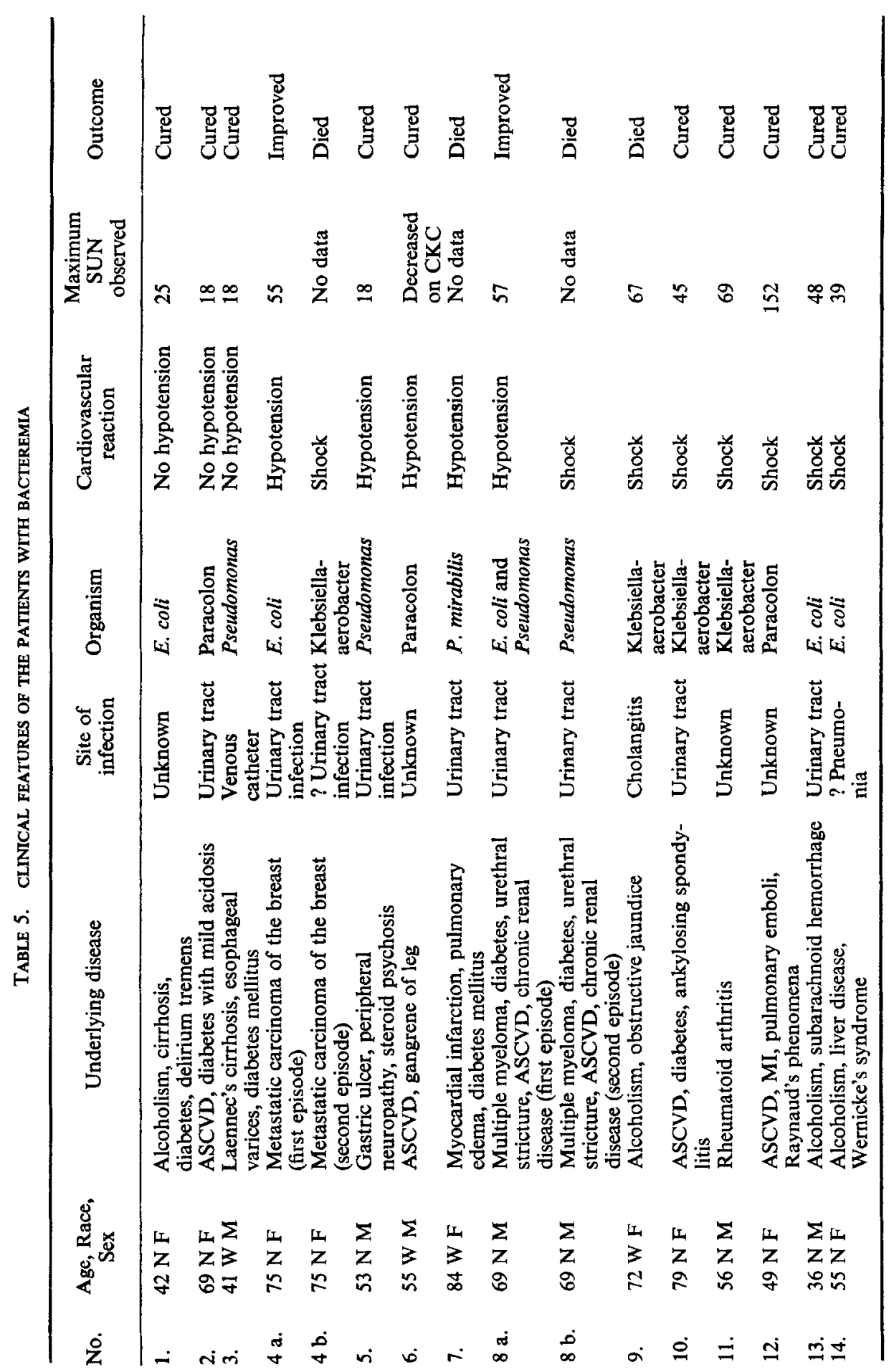




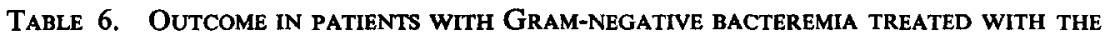
COMBINATION

\begin{tabular}{lccc}
\hline $\begin{array}{l}\text { Clinical condition } \\
\text { during the infection }\end{array}$ & $\begin{array}{c}\text { Number of } \\
\text { patients }\end{array}$ & $\begin{array}{c}\text { Number of } \\
\text { deaths }\end{array}$ & $\begin{array}{c}\text { Mortality } \\
\text { rate \% }\end{array}$ \\
\hline No hypotension & 3 & 0 & 0.0 \\
Hypotension (total) & 13 & 4 & 30.7 \\
Hypotension without oliguria & 5 & 1 & 20.0 \\
Severe hypotension with oliguria (shock) & 8 & 3 & 37.5 \\
Total episodes & 16 & 4 & 25.0 \\
Total patients & 14 & 4 & 28.6 \\
\hline
\end{tabular}

\section{Toxicity}

No hematologic toxicity was documented. A possible superinfection was noted in 2 patients; 1 developed mild cutaneous moniliasis. The other (Table 5) developed Klebsiella bacteremia and died after recovering from Esch. coli bacteremia. Gastrointestinal side effects were infrequent. Pain at the sites of injection or phlebitis at sites of intravenous administration were common. One patient developed fever probably attributable to drugs. No other hypersensitivity reactions were seen despite the fact that 5 patients had a history of drug allergy in the past, and 3 of them were probably allergic to penicillin.

Paresthesias (a well-recognized side effect of the use of colistin) occurred, but were not troublesome. Three patients underwent general anesthesia while receiving the combination, and none of them developed apnea. None of the patients developed gross ototoxicity or ataxia.

We summarized effects of therapy on serum urea nitrogen in Table 7. It must be emphasized that 68 per cent of the patients in this study were hypotensive, and that 86 per cent of those with bacteremia were hypotensive. Most of the patients received the combination for no more than 3 days, and 37 per cent of the patients receiving therapy for only 3 days developed elevations of the serum urea nitrogen. Elevation of the urea nitrogen (SUN) was more frequent when therapy was continued for more

TABle 7. EFFEct OF TREATMENT WITH CEPHALOTHIN, KaNAMYCIN, AND COLISTIN UPON THE SERUM UREA NITROGEN (SUN)

\begin{tabular}{lccccc}
\hline $\begin{array}{l}\text { Alteration } \\
\text { of SUN } \\
\text { during therapy }\end{array}$ & $\begin{array}{c}\text { Pre-treatment } \\
\text { SUN normal } \\
\text { (No. patients) }\end{array}$ & $\begin{array}{c}\text { Pre-treatment } \\
\text { SUN abnormal } \\
\text { (No. patients) }\end{array}$ & $\begin{array}{c}\text { Total number } \\
\text { and percentage } \\
\text { of grand total }\end{array}$ \\
\hline $\begin{array}{l}\text { Decrease } \\
\text { No change }\end{array}$ & 0 & 14 & 14 & $(30)$ \\
Transient increase & 11 & 3 & 14 & $(30)$ \\
Progressive increase in patients who died & $4 *$ & $3^{*}$ & $7^{*}$ & $(15)$ \\
Permanent increase in survivors & 4 & 7 & 11 & $(24)$ \\
\hline Total & 0 & 0 & 0 & $(0)$ \\
\hline
\end{tabular}

*All of these patients developed hypotension during this illness except for 1 who had bilateral obstruction.

†Four patients excluded because of inadequate data. 
TABLE 8

DURATION OF THERAPY WITH THE COMBINATION OF CEPHALOTHIN, RANAMYCIN, AND COLISTIN

\begin{tabular}{cc}
\hline Duration (days) & Number of patients \\
\hline 1 & 5 \\
2 & 7 \\
3 & 16 \\
4 & 5 \\
5 & 7 \\
6 & 2 \\
7 & 2 \\
8 & 1 \\
9 & 2 \\
10,11 & 0 \\
12 & 3 \\
\hline
\end{tabular}

than three days (it was noted in 57 per cent of these patients), but the difference between these groups was not significant $\left(\chi^{2}=1.9, p>0.1\right)$.

Nineteen patients had apparently normal renal function at the time the combination was begun. Four of them had transient elevations of the urea nitrogen; three had hypotension during their infection and the other had bilateral ureteral obstruction. Thirty-four patients developed hypotension during treatment; in 17 with a brief hypotensive episode the SUN decreased or remained stable during therapy, in 6 it became transiently elevated, and it rose progressively in eleven patients who died.

Twenty-seven, or more than 50 per cent of the patients, had impaired renal function at the time CKC was begun, and 24 ( 89 per cent) of these had hypotension as well. Renal function improved, as measured by the urea nitrogen, in 52 per cent of these patients after treatment (Table 7). In 10 ( 42 per cent) of 24 patients with hypotension as well as impaired renal function at the onset of the infection, the urea nitrogen rose still further during therapy. Seven of these 10 were patients who died of their basic disease. In the other three, the urea nitrogen was only transiently elevated and ultimately returned to the level observed prior to therapy.

Patients who survived the infection for which they were given the combination never demonstrated persistent evidence that their renal function had been impaired by the antibiotics, as measured by the SUN or serum creatinine*. Seven patients had transient elevations of the SUN during therapy. Most had severe underlying disease as well as hypotension and decreased renal perfusion.

Eleven patients treated with the combination had a rising SUN at the time of death. All of the patients had severe underlying disease, with multiple reasons for developing impaired renal function. Autopsies were performed on 6 of these patients. These showed tubular necrosis in 5 of the 6 patients. The problem of identifying the cause of these histologic findings has been discussed in greater detail in an earlier study of colistin (5).

The duration of treatment with CKC in our 50 patients is shown in Table 8 . The median and mean duration of therapy with these antibiotics were 3 and 4 days respectively. Ten of the 50 patients $(20$ per cent) received all 3 antibiotics for

\footnotetext{
*The upper limit of normal for SUN and creatinine was 19 and $1.2 \mathrm{mg} . / 100 \mathrm{ml}$, respectively.
} 
Table 9. Potential NePhrotoxicity in Patients With Gram-Negative bacteremia

\begin{tabular}{lccc}
\hline $\begin{array}{l}\text { Antibiotic } \\
\text { regimen }\end{array}$ & $\begin{array}{c}\text { No. developing } \\
\text { abnormal SUN or } \\
\text { serum creatinine }\end{array}$ & $\begin{array}{c}\text { Total } \\
\text { patients }\end{array}$ & $\begin{array}{c}\text { Percentage } \\
\text { abnormal }\end{array}$ \\
\hline No nephrotoxic antibiotics (susceptibility of & 12 & 23 & 52.1 \\
organism not always proven) & 4 & 14 & 28.6 \\
No nephrotoxic antibiotics (regimen appropriate) & 9 & 20 & 45.0 \\
Colistin (appropriate) & 6 & 14 & 42.9 \\
Cephalothin, kanamycin, and colistin (appropriate) & & & \\
\hline
\end{tabular}

6 or more days, and 3 patients were treated for a total of 12 days. The SUN in 8 of the 10 patients who were treated with the combination for more than 6 days remained normal or declined to normal during therapy. One of the remaining 2 patients treated for more than 6 days developed an elevation of the SUN from 14 to $63 \mathrm{mg} / 100 \mathrm{ml}$ during a possible episode of bacteremic shock. He subsequently died from a cardiac arrhythmia. The serum urea nitrogen of the other patient rose to $114 \mathrm{mg} / 100 \mathrm{ml}$ while he was being treated for severe necrotizing pancreatitis and shock. He recovered, and his SUN subsequently returned to normal. In both of these patients, other causes of azotemia in addition to nephrotoxic drugs were present.

We retrospectively reviewed the hospital records of 43 other adult patients with documented Gram-negative bacteremia. The results are presented in Table 9. Pencillin G, ampicillin, tetracycline, chloramphenicol, and streptomycin were assumed not to be nephrotoxic for this analysis. It was apparent that nephrotoxicity was frequent even when relatively safe antimicrobials were given (28.6 per cent), and CKC did not seem to be worse than colistin alone.

\section{DISCUSSION}

Our therapeutic results compare favorably with those reported in the literature [4], but we do not wish to make any claim that the combination of CKC is more efficacious than a variety of other popular regimens. The number of cases with bacteremia we have seen thus far is small. Furthermore, we believe that a number of other measures now in common use in treatment of patients with Gram-negative infection may contribute to better survival rates. These include the monitoring of central venous pressure, more intelligent replacement of intravascular fluid deficits, a more rational use of vasoactive amines and the use of pharmacological doses of adrenal steroids. We believe it is bad to treat patients with sepsis with adrenal steroids unless they are receiving appropriate antibiotics, and this is one of the reasons we have been encouraged to pursue our studies with CKC.

In severe infections with bacteremia, our data suggest that the combination of cephalothin, kanamycin, and colistin can be used with safety, and that it assures excellent antibacterial activity against a wide range of organisms early in the course of infections. Once the nature of the infection is established, the regimen frequently can and should be modified so that less toxic antimicrobial drugs are used. That we observed no serious nephrotoxicity definitely attributable to the antibiotics justifies no complacency, since two of these antibiotics have well recognized nephrotoxic potentials. Our data show that the risk of serious nephrotoxic reactions is not prohibitive in these patients, but we believe such reactions will undoubtedly occur from time to time. 
While most of these patients were treated with colistin methanesulfonate, this antibiotic is closely related to polymyxin $B$, and it is likely the results are equally applicable to the latter antibiotic used in appropriate and recommended amounts.

\section{SUMMARY}

Fifty hospitalized adults suspected of having Gram-negative bacteremia were treated with cephalothin, kanamycin, and a polymyxin. Sixteen episodes of bacteremia in 14 patients were documented. Urinary tract infections and pneumonia were most frequent. All bacteria isolated from these patients were susceptible to 1 or more of the antibiotics used. Four of 16 episodes of bacteremia ended fatally. Three of 8 patients with bacteremia and shock died.

Most of the patients developed hypotension or shock during infection. Fifty-nine per cent had evidence of impaired renal function before treatment, but only 40 per cent of all patients manifested deterioration of renal function during therapy. Acute tubular necrosis was frequently found in those with bacteremia who died. No survivors showed evidence of permanent impairment of renal function. We believe this combination of antibiotics is beneficial, and can be used safely by those familiar with its hazards.

Acknowledgements - We thank Robert Heptinstall, M.D., Acting Chairman, Department of Pathology, The Johns Hopkins Hospital, for reviewing the histologic specimens from kidneys of autopsied patients; and we are grateful to Phyllis Partain for her technical assistance.

\section{REFERENCES}

1. Bailey WR, Scott EG : Diagnostic Microbiology. St. Louis, Mosby, 1966

2. Fekety FR, Cluff LE: Studies on the antibiotic therapy of serious staphylococcal infections. Ann Intern Med 56: 198-206, 1962

3. Fekety FR, Weiss P: Antibiotic synergism : enhanced susceptibility of enterococci to combinations of streptomycin and penicillins or cephalosporins. Antimicrob Agents Chemother $156-164,1966$

4. Hodgin UG, Sanford JP: Gram-negative rod bacteremia. Am J Med 39: 952-960, 1965

5. Fekety FR, Norman PS, Cluff LE: The treatment of Gram-negative bacillary infections with colistin. Ann Intern Med 57: 214-229, 1962

6. Kunin CM : Nephrotoxicity of antibiotics. J Am Med Ass 202: 204-208, 1967 